\title{
THE CULTURAL COMPETENCE PORTFOLIO AS A LONG-TERM INNOVATION FOR ALL LEVELS OF EDUCATION
}

\author{
Austra Avotina \\ University of Latvia, Latvia
}

\begin{abstract}
The paper describes the cultural competence portfolio, which is an innovative approach to the organisation and evaluation of the study process. This includes an active involvement of various study process components: creative work, expression of original ideas, recording of the research process and prevalent self-evaluation. The relevance of the subject of this paper is highlighted by the ongoing education reform in Latvia, which is built around a purposeful, systematic competence development in eight of the basic components for lifelong learning (European Parliament recommendations of Key competences for lifelong learning - 2006/962/EC). One of these components is cultural awareness and expression. The research consists of three parts:

- the portfolio approach in the study process;

- cultural competence as a quality indicator of the education;

- specific options of realisation and evaluation.

According to the definition, a portfolio is a collection of artefacts, materials and works, accumulated over a certain period of time and it includes three equally important elements of the competence: knowledge, skill and attitude. The portfolio demonstrates accomplishments of a study process and serves as a positive self-evaluation in one or several areas. The portfolio approach can be used in different areas, but it has an especially high value in culture and arts studies. Therefore, the main topic of the research is the cultural competence portfolio in particular, which can ensure the compliance with the education levels, defined by the European Qualifications framework (EQF).

The cultural competence portfolio is a collection of personal documents, which can and preferably should be supplemented, re-organised and changed over a long-term period in line with its aims. Such portfolio is a tool to fulfil the aim of education and to reflect on some specific achievement. Not only is it an important tool in the areas of culture and art for actors, musicians, architects, and models but also for every, student and human, who intentionally wants to develop his / her cultural competence as a lifelong process.
\end{abstract}

Keywords: Portfolio, Cultural competence, Learning methods, Long-term innovation. 


\section{Introduction}

There are two reasons that substantiate the topicality of this paper. The first is the rapid development of new technologies and digital communication, cognitive tools and everyday reality. This has created a necessity to introduce in practice such teaching/learning methods that would reveal the value of the digital information flow and would correspond to the new requirements of the society, explaining the study process as a long-term innovation on all levels of education. Therefore, the emphasis should be laid on switching from a ready to use knowledge to a guided learning. This process has already been started, and it is especially topical at the university-level studies. Due to this reason, the paper explores on the study dealing with the impact of the development of the portfolio on the study process. After the first two steps are completed, the final assessment will be provided. The experiment was carried out in the Medieval art history course within the bachelor study programme at the Latvian Academy of Art It was performed from 2016 till 2018, involving 145 second year students.

The second reason is the education reform of Latvia implemented in the frame of the National Centre for Education project "Competence-based approach in the teaching/learning content" (Skola2030, 2019). Its aim is to work out, pilot and then introduce successively innovative changes in the teaching/learning approach. What is at the heart of this reform is that students should be capable of applying their knowledge and skills acquired at school in real life situations; they should develop a deeper understanding of subject in each teaching/learning domain. In order to achieve this, the learner should be at the centre of the study process; he / she should learn to think, cooperate, seek answers. This suggests that each student should be able to construct the meaning of the acquirable content. Within the framework of the project, a survey was carried out in the second part of 2018. It involved 737 parents and 3304 students from 327 schools of Latvia. (as respondents). The project manager Olina points out that the aspects that have been identified during the survey complies with the offered new teaching/learning content. It provides broader aims for education as it is envisaged to acquire also general skills or transversal skills, to cultivate value-based habits, the skill to apply the knowledge in complex situations along with the knowledge at school. The fragmentation and the scope of the teaching/learning content is reduced to the emphasis on interconnections and interdisciplinarity. In their answers, students have expressed the desire for a personalized approach to the teaching/learning process. They feel that sometimes their diligence and invested work is undervalued. Thus, students and their parents consider that the assessment system should be oriented 
towards the personal growth. Students also indicate that they wish their contribution, the invested work, attitude and diligence were also assessed, even if the final performance or outcome is with mistakes (Skola2030, 2019). The answers, particularly, support the conclusion, which is also important in the context of this paper: the assessment is inadequate in the subjects of culture understanding and art domain. Consequently, when grading subjects such as art and music, the teachers should consider specific aspects, for example talent being one of them. This will definitely lead to a better structured and understandable way of assessment.

Students are offered to compile a cultural competence portfolio as one of the methods and innovative ideas in the context of the Educational system of Latvia, which would serve both as the reflection of the learning process and the indicator of personal growth. Additionally, it is going to demonstrate the usefulness of outcomes and demonstrate the attitude contribution, efficiency, the invested work and diligence.

Both reasons are topical on all levels of education and lifelong learning. (And the above-mentioned topicalities have defined the idea of this paper). Therefore, the aim of the paper is to discuss the approach of compiling the cultural competence portfolio as a long-term innovation and reveal a learner's attitudes towards forming a portfolio as an opportunity for applying it as a quality indicator of education. Three objectives are set for the research analysed in this paper:

- to determine the place of the portfolio approach in the study process;

- to argue that cultural competence may serve as a quality indicator of education in the in the era of visual communication and information technologies;

- to give some examples of specific options of realisation and evaluate status quo.

Several questions can be put forward in the context of the aim. What is a portfolio in education? What is the cultural competence portfolio? How to increase the learning motivation and how to assess attitude and what is the correlation between each other?

\section{Methodology}

A portfolio as a learning method (Paulson, 1991, Hamp-Lyons, 2000, Grosch, 2003, Adamski, 2003, Winter, 2015) is emphasized by distinguishing three types of a portfolio (personal, professional and study). The second part of the paper substantiates the acknowledgement of the cultural competence portfolio as the learner's personal growth indicator. Its introduction in the teaching/learning process can improve the study programmes, thus, (being able to implement?) implementing 
a meaningful learning process? (Sauleniene, 2015, Dellen, 2012, Milson, Brantley, 1999). The third part, referring to the samples of history portfolio, describes a concrete task of the study process. The results are elucidated with some concrete data obtained from a practical study about the impact of the portfolio on the study process.

\section{The portfolio approach in the study process}

The term portfolio is widely used and is especially well-known in art professions. It serves as a proof of the professional mastery and usually is a collection of pictures, papers or ideas. In the etymological sense, portfolio portare (Latin) means: to have or hold; folio - paper, sheet of paper; protefeuille (French) means - carry (porter) sheet (feuille); portable folder for papers, books, textbooks, notebooks. In the study process, it means a selection of a student's work (such as papers and tests) compiled over a period of time and used for assessing his / her performance or progress (Portfolio, 2019). The first precise definition of what portfolio is in the teaching/learning context has been developed and presented in a conference in ... already in 1990 but published a year later: "A portfolio is a purposeful collection of student work that exhibits the student's efforts, progress, and achievements in one or more areas. The collection must include student participation in selecting contents, the criteria for selection, the criteria for judging merit, and evidence of student self-reflection" (Paulson, 1991, 60). Eight guidelines that (would) promote self-guided learning are mentioned and the strength and importance of this idea are substantiated. For instance, what is especially topical in 2020 , i.e., 30 years later - is the third comment about the importance of the so-called student's cumulative folder. Nowadays, many people have such a folder with a collection of pictures and texts. They can be stored as an e-portfolio (digital portfolio). Whatever richness of information they had in the files, the portfolio should only include the information that provides some context with the rest of the collected material. The author then can allocate a new value this material through the already developed context. This is a direct answer to the topical question - does the wide accessibility of information already solve the topicality of learning? It is possible to claim that only such information, which has its particular place in the existing notions (thus, the principle of self-evident succession) and to which its acquirer can allocate the context meaning (thus, already the meaning of application) is useful for further studies? The information itself (whether it is copied or available only digitally) cannot help much if it has not found a concrete place and if it does not form a context with what has been known before. A certain level of competence (corresponding to the learner's age group) is needed for establishing the context. Therefore, the use of both words together directly refers to the learning process. The term means an organized set of factual 
materials, individual works and projects, which have been collected over a definite period of time and serve to reflect the learning achievements, skills and attitude. In essence, it is a tool for positive self-assessment in one or several areas or subjects.

\section{Cultural competence as a quality indicator of the education}

The competence is considered to be a wider concept than knowledge and skills. It includes also motivation and attitude in its cognitive and socially ethnic facets (Cedefop, 2014). The competence can be learned (Nordenbo, 2008, 70). This is especially important for developing the indicators, because it is important to understand the contribution of the education towards the development of competence. Similar to portfolio the competence has two dimensions - an external and an internal dimension.

The cultural competence encompasses analytical knowledge, positive and simultaneously interested understanding of cultural heritage, the significance of a cultural era phenomenon and its emergence types (knowledge); the necessity and skills to apply the cultural values, to evaluate and create new ones, thus developing new learning methods (skills); a developed capability to evaluate the interrelationships and motivation and selfevaluative attitude to act creatively and actively as well as in accordance with cultural topicalities of the era (attitude). All three mentioned parts of the competence are reflected in the content of the competence portfolio. The depth of the knowledge (the scope of facts) and their arrangement and comments (skills), the structure and appearance of the portfolio, which show the attitude, can be assessed. The content of cultural competence portfolio represents an organized set of factual materials, own works and projects, which have been collected over a definite period of time and serve to reflect the learning achievements, skills and attitude. Actually, it is a tool for positive self-assessment in one or several areas. The portfolio can be compiled in two ways. One is the- so-called "external" way, which comprises everything that corresponds to the aim and can be found in the study process, and the other; the-so-called, "internal" way contains the reflection of the student's learning process - the personal contribution, growth and work with the "external" part (Sauleniene, 2015). The selection of the collected materials has been performed; comments, reviews, critical analyses, drawings, digital collections, etc. have been carried out. The "internal" part of the portfolio is the most important one. The personally significant, meaningful, experienced and reflected material comprises its content. "When being compiled during studies, the competence portfolio can help to improve study programmes and ensure deeper and more meaningful studies" (Sauleniene, 2015, 92). It is the practical part of the teaching/learning process the importance of which is especially emphasised in the education reform. 


\section{Specific options of realisation and evaluation}

It is also possible to define the structure of the portfolio. Firstly, it is a reflection (questions, contemplations) about all that has been heard, seen, experienced - the selection has to be done depending on the aim and objective of the portfolio (it can be thematically narrow, interdisciplinary, devoted to the particular project, etc.). Secondly, it is an annotated bibliography which means a collection of the collected materials documents, books, internet sources, music, etc. and comments on them. This part includes also study materials - self-control tests, tasks, etc. A significant condition is a systematic work with these materials during a particular time period, namely, to develop metacognitive skills and to apply them purposefully. The teacher's assistance is needed here; therefore, the self-evaluation process should be structured and it must be analysed together (both in mutual cooperation with and under the teacher's guidance). This fosters the habit of thinking (reflecting) on what is known and what happens during the teaching/learning process. "As students select items for inclusion, they are expected to develop and express clear rationales for how these items demonstrate knowledge acquisition and reflective thinking" (Milson, Brantley, 1999, 375). This develops purposefulness and habits of practical (rational) action and allows avoiding the inclusion of ungrounded or formally added materials.

The practical part of the learning process is very important; it should include visits to exhibitions, purposeful tours and trips. The activities should be well-considered and targeted. Students should reflect on the activities by writing essays, critiques or reports. Everything that has been experienced is noted and reflected upon. An artists' portfolio mainly consists of drawings. In this case, drawing is similar to thinking. It is a process which records the retrospectively important experience. In history, there are many examples which show that the collections of sketches and drawings have formed a self-guided (lifelong learning) process. Very often it is a process caused only by the-so-called self-initiative (initiated by self-motivation). It is worth here highlighting three differently preserved examples, whose cultural, historical and pedagogical importance are invaluable. The first to be mentioned is Johann Christoph Brotze (Broce, 1742-1823), a teacher, historian and ethnographer of Livonia. Brotze's heritage is a unique portfolio containing thematically, factually and chronologically diverse, but unsystematic materials, including a large number of unique - anywhere else not documented - historical references. There is an impressive collection of Brotze's drawn and collected pictures: 10-volume manuscript Sammlung verschiedner Liefländischer Monumente, Prospect, Müntzen etc. (Taimina, 2013, 18). This portfolio demonstrates not only J. K. Brotze's personal interest in the history of culture but also the reflection of the Livonian 
society of the $18^{\text {th }}$ century - it serves as a mirror of knowledge, skills and attitudes. This is a collection with a unique, wide-scale value.

The second example, also important in the context of this paper, is Leonardo da Vinci Codex Arundel. Notebook of Leonardo da Vinci (Leonardo da Vinci, 1452-1519). It is a portfolio (1480-1518) of completely self-guided, unstoppable and ravenous process of research and analysis, the collection of contexts and inventions, created by one author. It consists of notes, diagrams, drawings, texts, covering a wide range of topics in science and art. Some personal notes (on 283 paper sheets) are also included. Leonardo has described it as "a collection without order, drawn from many papers, which I have copied here, hoping to arrange them later each in its place according to the subjects of which they treat" (Leonardo da Vinci, 1518). It should be mentioned that he himself failed to structure it. It is only one example that proves the necessity to structure and arrange one's portfolio materials since the very start - and this should be taught to every student already at an early age.

The third example is directly connected to the qualitative research, in which the obtained data serve as evidence for the positive impact of the portfolio on the teaching/learning process. The author used the study portfolio of the artist and architect - Villard de Honnecourt (Vilars de Honecourt, before 1230 - after 1235), who lived in the $13^{\text {th }}$ century, as the source of inspiration for this task. It is the oldest known portfolio of such a type. The author has recorded buildings, people, clothing, furniture, household items, animals, details, tools, inventions etc.. These are 33 parchment sheets with 250 drawings, which are the most important original source from the High Gothic about the architecture and methods of construction (Honnecourt, 1906). Inspired by these, students received a task to form a portfolio of drawings with 33 sheets as a minimum, to provide substantiation for the idea and comment on each of the drawings about the source and the reason for including it in the portfolio. Those could be sketches in nature (time, place in relation to the Middle Ages?) and collected images (with indicated source, value, importance to medieval research). (The qualitative research obtained data about the impact of compiling a portfolio on the study process and the final assessment in the Medieval art history course in the bachelor study programme at the Latvian Academy of Art. The research was performed from 2016 till 2018 and it involved 145 second year students.) The following were set as the assessment criteria - the size, uniqueness of an object, choice, imagination and vision when drawing modern objects Additional items such as professional substantiation and their relationship to the medieval ideas were required to be included. The format was not prescribed, and this allowed students to express themselves in the most diverse ways - as 
a result, miniature masterpieces in octavo format $(170 \times 108 \mathrm{~mm})$, and large parchment-like sets of pages in the folio format $(445 \times 307 \mathrm{~mm})$ were received; each student had a possibility to find the format and technique that corresponded to his/her artistic way. An approach to apply the methods of the chosen art studies area was suggested, e.g., students of the glass study department were advised to study stained glass in more detail but sculpture department students - works of sculpture. A prerequisite of such a task is the length of the study course which cannot be shorter than 20 weeks because the compilation of the portfolio occurs along with the study process. The instructor encouraged students to study literature and digital sources. This was done with a purpose to improve the drawing skills of students. The particular approach however, was not assessed as academic professionality. Each of the above-mentioned criteria needs broader comments, which are subject to a separate paper.

\section{Results}

The description of results includes the qualitative data which was obtained during the examination days when giving back the portfolio materials to the students. Then the benefits of this task were discussed, and the students expressed their opinion about such an assessment form. As the research includes three student groups from different study years, the data were structured according to these years and summarised in the spring of 2019. The research participants were in total 145 respondents in average age of 20 years and of various art programs at the Latvian Academy of Arts. During the exam, students took part in interviews. They provided answers to the same 5 questions; the results are summarised in Table 1. After the interviews, the answers were coded und differentiated on three levels.

As seen in Table 1, all in all students' attitude to this task was very positive. The average indicator of a very positive assessment of the task is $70 \%$. It is important to indicate that $9 \%$ of students who have not considered the task useful actually are the ones who have not attended the classes (or have done it rarely). Thus, they have been outside the common study atmosphere and its impact. A significant indicator are the answers to the fifth question, where positive ("fully agree") answers are only 54\%. This shows a low self-assessment, probably the inability or the lack of experience in assessing one's own work. Another important indicator is that with every next year and especially in the third year the number of positive assessments continued to increase. This allows to conclude that there is inter-communication among students and the positive attitude has been spread; thus - the disposition to such a task becomes more positive and 
is taken for granted. So, it is possible to change the conditions of the task, enlarging the depth of the study and solving the possible options in order to introduce reciprocal evaluation. In case of the portfolio, their display for general viewing was problematic, and it took a rather long time to receive the assessment. But such a solution would give an additional value to this task because students would gain their own experience and understanding about different ways of visual expression, different ways of thinking and perception of the study content.

Table 1. Qualitative survey (individual discussion) about the importance of the portfolio in the study process.

\begin{tabular}{|c|c|c|c|c|c|c|c|c|c|}
\hline Academic year & \multicolumn{3}{|c|}{$2016 / 2017$} & \multicolumn{3}{|c|}{$2017 / 2018$} & \multicolumn{3}{|c|}{$2018 / 2019$} \\
\hline Number of students & \multicolumn{3}{|c|}{53} & \multicolumn{3}{|c|}{48} & \multicolumn{3}{|c|}{44} \\
\hline Commented opinion & $\begin{array}{l}\text { Fully } \\
\text { agree }\end{array}$ & $\begin{array}{l}\text { Partly } \\
\text { agree }\end{array}$ & $\begin{array}{c}\text { Dis- } \\
\text { agree }\end{array}$ & $\begin{array}{l}\text { Fully } \\
\text { agree }\end{array}$ & $\begin{array}{l}\text { Partly } \\
\text { agree }\end{array}$ & \begin{tabular}{|c} 
Dis- \\
agree
\end{tabular} & $\begin{array}{l}\text { Fully } \\
\text { agree }\end{array}$ & $\begin{array}{l}\text { Partly } \\
\text { agree }\end{array}$ & $\begin{array}{c}\text { Dis- } \\
\text { agree }\end{array}$ \\
\hline $\begin{array}{l}\text { 1. Did the compiling } \\
\text { of the portfolio help/ } \\
\text { motivate for deeper } \\
\text { studying? }\end{array}$ & 35 & 10 & 8 & 32 & 8 & 8 & 37 & 5 & 2 \\
\hline $\begin{array}{l}\text { 2. Has the compiling of } \\
\text { the portfolio changed } \\
\text { the initial views about } \\
\text { the medieval culture } \\
\text { and art? }\end{array}$ & 33 & 15 & 5 & 29 & 14 & 5 & 39 & 5 & 0 \\
\hline $\begin{array}{l}\text { 3. Would it be } \\
\text { beneficial to use such } \\
\text { a form of tasks also in } \\
\text { the acquisition of other } \\
\text { periods in the history } \\
\text { of art? }\end{array}$ & 28 & 20 & 5 & 34 & 10 & 4 & 39 & 3 & 2 \\
\hline $\begin{array}{l}\text { 4. Has the compiling } \\
\text { of the study portfolio } \\
\text { helped the professional } \\
\text { development? }\end{array}$ & 42 & 8 & 3 & 40 & 8 & 0 & 37 & 5 & 2 \\
\hline $\begin{array}{l}\text { 5. Do you consider } \\
\text { your portfolio } \\
\text { interesting, useful and } \\
\text { artistically important } \\
\text { material? }\end{array}$ & 26 & 18 & 9 & 28 & 10 & 10 & 25 & 15 & 4 \\
\hline Total : 5 questions & $164: 5$ & $71: 5$ & $30: 5$ & $163: 5$ & $50: 5$ & $38: 5$ & $177: 5$ & $33: 5$ & $10: 5$ \\
\hline Percent of students & $62 \%$ & $27 \%$ & $11 \%$ & $68 \%$ & $21 \%$ & $11 \%$ & $80 \%$ & $15 \%$ & $5 \%$ \\
\hline
\end{tabular}

The second correlation that was stated and which is a significant indicator of the portfolio's impact on the study process is the quality of the final assessment. When summarizing the research data, a question was posted whether a link existed between high assessment of the portfolio 
and the assessment of the examination work. It was established that out of 145 respondents 65, who had received high assessment of their portfolio, had also passed the examination with an excellent, very good or good mark. However, it is only $44 \%$ of the total number of respondents. This result shows that even before getting the assessment in the examination, there are more those students who have expressed a positive attitude to the compiling of the portfolio (70\%). It serves as evidence that there will always be students who are willing to perform different practical tasks but are not ready to participate in the theoretical part (acquisition of knowledge) of the study process. In all cases, when students received the highest mark in the examination, their portfolio had also been highly assessed. There are rather few cases, when it did not correlate, and the reasons are various as admitted by students themselves - it has been the lack of time, illness, unexpected situations, laziness, etc.

\section{Conclusions}

1. Portfolio is a compilation of academic work and other forms of educational evidence assembled for the purpose to reveal the learning process; it is an essential tool both for students and educators.

2. Any portfolio in its substance is a cultural competence portfolio. It is a "living" document, which can be always supplemented, restructured and expanded to meet the goals. It is a personal document, which becomes a tool to accomplish the academic goals.

3. Reflection is an important component of the portfolio method. It is crucial not only to collect the documents in it but also to have a clear understanding, what and why is compiled in it.

4. The portfolio is an alternative assessment method with formative value for students that fosters the learning motivation in a positive way.

5. Students and teachers can use the portfolio as a basis for discussion and reflection on the academic achievements and learning process due to the "living nature" of the portfolio.

The compiling of the cultural competence portfolio improves the learning outcomes. It promotes self-guided learning, helps to memorize the chosen (significant) facts, deepens the understanding and affects positively students' attitude to the learning process in general, which, in turn, facilitates the cooperation skills, positive attitude and the realization of motivated learning in the study process becoming a long-term innovation in the context of lifelong education. 


\section{References}

Adamski, P. (2003). Bewertungsprobleme bei Portfolio- und Projektarbeit [Evaluation problems in portfolio and project work]. Retrieved from https://www.nibis.de/ uploads/1chaplin/files/Adamski_Bewertungsprobleme_bei_Portfolio.pdf.

Cedefop (2014). Terminology of European education and training policy: a selection of 130 terms. 2nd ed. Luxembourg: Publications Office. Retrieved from https://www.cedefop.europa. eu/en/events-and-projects/projects/validation-non-formal-and-informal-learning/ european-inventory/european-inventory-glossary.

Dellen, A., van. (2012). Zertifikat Lehrkompetenz [Certificate teaching competence]. Insbruk: Institut für Praktische Theologie. Retrieved from https://www.uibk.ac.at/ rektorenteam/lehre/die-lehre-seite/schaufenster/publikationen/alexander-van-dellen. pdf.

Grosch, W. (2003). Evaluation, Lernkontrolle und Leistungsbewertung [Evaluation, learning control and performance evaluation]. In H. Günther-Arndt (Hrsg.), GeschichtsDidaktik. Praxishandbuch für die Sekundarstufe I und II [History of didactics. Practical handbook for secondary education I and II]. Berlin: Cornelsen Verlag Scriptor Gmbh\&Co.K.G. 206-218.

Hamp-Lyons, L. (2000). Assessing the portfolio. Principles for practice, theory, and research. New Jersey, Hampton Press.

Honnecourt, V. (1906). Album de Villard de Honnecourt. Retrieved from https://archive. org/details/albumdevillardde00vill/page/n61.

Leonardo da Vinci (1518). Codex Arundel. Notebook of Leonardo da Vinci. Handwriting of Leonardo da Vinci. Retrieved from http://www.bl.uk/manuscripts/FullDisplay. aspx?ref=Arundel_MS_263.

Milson, A. J., Brantley, S. M. (1999). Theme-based portfolio in social studies teacher education. Retrieved from www.socialstudies.org/sites/default/files/publications/ se/6306/630613.html.

Nordenbo, S. E., Larsen, M. S., Tiftikci, N. (2008). Teacher competences and pupil achievement in pre-school and school. A systematic review carried out for The Ministry of Education and Research, Oslo, Copenhagen, School of Education University of Aarhus.

Paulson, L., Paulson, P., Meyer, C. (1991). What makes a portfolio a portfolio? Educational Leadership, 48(5), 60-63. Retrieved from https://web.stanford.edu/dept/ SUSE/projects/ireport/papers/e-portfolio/.

Portfolio (2019). Webster Dictionary. Retrieved from https://www.merriam-webster. com/dictionary/portfolio.

Sauleniene, S. (2015). The competence portfolio as the reflection of learner's qualitative change and attitudes towards learning. Scriptus Manet. Humanitāro un mākslas zinātnuu žurnāls [Journal of the Humanities and the Arts]. Liepāja, 2015 (2), 84-94.

Skola2030. (2019). Jo mūsdienigākas metodes izmanto skolotāji, jo vairāk apmierināti ar skolu un mācībām ir skolēni [The more contemporary methods teachers use, the more satisfied students are with school and learning]. Retrieved from https://www.skola2030.lv/.

Taimina, A. (2013). Johann Christoph Brotze's (1742-1823) biography and his manuscripts collection in the Academic Library of the University of Latvia. Riga, University of Latvia.

Winter, F. (2012). Das Portfolio vom möglichen Mehrwert her planen [Plan the portfolio starting from the possible added value]. In: Bräuer, G., Keller, M., Winter, F. (Hrsg.). Portfolio macht Schule [Portfolio makes school]. Seelze: Klett/Kallmeyer, 41-65. 